\title{
Lessons Learned from Implementing Clostridium difficile-Focused Antibiotic Stewardship Interventions
}

\author{
B. Ostrowsky, MD, MPH, FSHEA; $;^{1,2}$ R. Ruiz, PhD, ScM; ${ }^{3}$ S. Brown, MPH; ${ }^{1}$ P. Chung, PharmD, MS; ${ }^{1,2}$ \\ E. Koppelman, MSW; $;^{4}$ C. van Deusen Lukas, EdD; ${ }^{4}$ Y. Guo, PharmD; $;^{1,2}$ H. Jalon, MS; $;^{5}$. Sumer, MS; ${ }^{3}$ \\ C. Araujo; ${ }^{3}$ I. Sirtalan, PhD ${ }^{3}$ C. Brown, MD; $;^{1,2}$ P. Riska, $\mathrm{MD}^{1,2}$ B. Currie, MD, $\mathrm{MPH}^{\mathrm{I}, 2}$
}

овјестіVE. To determine whether controlling the prescription of targeted antibiotics would translate to a measurable reduction in hospital-onset Clostridium difficile infection (CDI) rates.

DESIGN. A multicenter before-and-after intervention comparative study.

SETTING/PARTICIPANTS. Ten medical centers in the greater New York region. Intervention group comprised of 6 facilities with early antimicrobial stewardship programs (ASPs). The 4 facilities without ASPs made up the nonintervention group.

INTERVENTIONS/METHODS. Intervention facilities identified target antibiotics using case-control studies and implemented ASP-based strategies to control their use. Pre- and postintervention hospital-onset CDI rates and antibiotic consumption were compared for a 20 month period from June 2010 to January 2012. Antibiotic usage was compared using defined daily dose, days of therapy, and number of courses prescribed. Comparisons used bivariate and regression techniques.

RESULTS. Intervention facilities identified piperacillin/tazobactam, fluoroquinolones, or cefepime (odds ratio, 2.0-9.8 in CDI case patients compared with those without CDI) as intervention targets and selected several interventions (all included a component of audit and feedback). Varying degrees of success were observed in reducing antibiotic consumption over time. Total target antibiotic use significantly decreased $(P<.05)$ when measured by days of therapy and number of courses but not by defined daily dose. Intravenous moxifloxacin and oral ciprofloxacin use showed significant reduction when measured by defined daily dose and days of therapy $(P \leq .01)$. Number of courses with all forms of these antibiotics was reduced $(P<.005)$. Intervention hospitals reported fewer hospital-onset CDI cases $(2.8$ rate point difference) compared with nonintervention hospitals; however, we were unable to show statistically significant decreases in aggregate hospital-onset CDI either between intervention and nonintervention groups or within the intervention group over time.

CONCLUSions. Although decreases in target antibiotic consumption did not translate into reductions of hospital-onset CDI in this study, many valuable lessons (including implementation strategies and antibiotic consumption measures) were learned. The findings can inform potential policy decisions regarding incorporating control of CDI and ASP as healthcare quality measures.

Infect Control Hosp Epidemiol 2014;35(S3):S86-S95

The past decade has witnessed significant reductions in healthcare-associated infections linked to infection prevention and control bundle initiatives. ${ }^{1,2}$ Unlike other healthcareassociated infections, the rates, severity, and complications from Clostridium difficile infection (CDI) have largely remained stable or increased throughout the United States. ${ }^{3-7}$ Because of these factors, finding effective ways to reduce the incidence of CDI has garnered increased attention in recent years from the medical community and public health and professional organizations. Controlling CDI is complex because several factors are likely involved, including infection control breaches, inadequate environmental cleaning, and unrecognized transfer of cases between facilities that can affect transmission. ${ }^{8}$ Since exposure to antimicrobials and hospitalization are also major CDI risk factors, antimicrobial stewardship programs (ASPs) have been suggested as an additional viable way to reduce the incidence of CDI. ${ }^{9,10}$

ASPs have been demonstrated to impact prescribing but in general have had difficulty in demonstrating measurable impact on more concrete clinical outcomes, such as antibiotic resistance., ${ }^{9,10}$ The ASP community has looked toward reducing CDI as a possible outcome for ASP activities, even as hospitals struggle with how to translate guidelines into actual stewardship activities and how best to measure antibiotic use and stewardship outcomes.9,10

The Evaluation and Research on Antimicrobial Steward-

Affiliations: 1. Montefiore Medical Center, Bronx, New York; 2. Albert Einstein College of Medicine, Bronx, New York; 3. Greater New York Hospital Association, New York, New York; 4. Boston University School of Public Health, Boston, Massachusetts; 5. United Hospital Fund, New York, New York.

Received May 1, 2014; accepted May 5, 2014; electronically published September 15, 2014.

(C) 2014 by The Society for Healthcare Epidemiology of America. All rights reserved. 0899-823X/2014/35S3-0013\$15.00. DOI: 10.1086/677828 
ship's Effect on Clostridium difficile (ERASE C. difficile) Project described in this study was designed to build on a previous CDI bundled reduction collaborative focused on improving infection control and environmental cleaning practices, which did not address the use of antimicrobials. ${ }^{1}$ ERASE $C$. difficile evaluated the development and implementation of ASP activities focused on reducing CDI among hospitals that all previously demonstrated high compliance with environmental and infection control bundle interventions (via the previous collaborative). The main objective was to determine the feasibility of controlling $C$. difficile-specific antimicrobial prescribing and whether this would translate to a measureable reduction in hospital-onset CDI rates.

\section{METHODS}

\section{Facility Recruitment}

Acute care hospitals in the greater New York region with a minimum burden of $10 \mathrm{CDI}$ cases per calendar quarter and prior participation in the Greater New York Hospital Association/United Hospital Fund (GNYHA/UHF) C. difficile Collaborative (March 2008-December 2009) were eligible to participate in the ERASE C. difficile Project. ${ }^{11}$ All hospitals had previously demonstrated more than $80 \%$ compliance with previous infection control and environmental services CDI bundle interventions. Of the 35 eligible hospitals, 11 were invited and 10 participated. The ASP intervention group had 6 hospitals with very early ( 2 years or fewer at initial recruitment) ASPs (a dedicated team of pharmacists and physicians with infectious diseases expertise to promote judicious antimicrobial prescribing), and the non-ASP intervention group included 4 hospitals without ASPs.

\section{Definitions, Data Collection, and Selection of ASP Targets}

Infection control and environmental cleaning. Implementation and monitoring of standardized infection control and environmental cleaning protocols continued as implemented during the GNYHA/UHF $C$. difficile collaborative. ${ }^{11,12}$ Infection control focused on using contact precautions, personal protective equipment, appropriate hand hygiene, and dedicated thermometers for $C$. difficile patients (when disposable options were not available). Environmental cleaning focused on how specific surfaces or areas were cleaned during routine and terminal room cleaning. This included observation by infection control and environmental supervisors, which were self-reported for each facility. Quantifying continued compliance with the previous $C$. difficile prevention practices was important to protect against confounding.

Selection of antibiotic targets and ASP interventions. Each intervention hospital performed its own case-control study on adult (18 years or older) inpatients, which was designed to identify the antibiotics or antibiotic classes associated with CDI. ${ }^{13}$ The case control was limited in that it mainly focused on antibiotics associated with CDI (not all exposures associated with CDI). A minimum of $33 \mathrm{CDI}$ cases were obtained from the Centers for Disease Control and Prevention's National Healthcare Safety Network (NHSN) between March 2010 and May 2010. Control cases were adult inpatients free of CDI for 3 months before or after their diagnosis matched by age ( \pm 5 years) and admission date ( \pm 5 days) to achieve a $2: 1$ control : case ratio. ${ }^{13}$

Odds ratios were used to compare antibiotic use between the case and control groups at each hospital. Statistically significant odds ratios and evaluation of prescription frequency were used to identify preliminary antibiotic targets. Final targets were selected after an internal medication review of prescribing patterns (eg, who prescribed the drug, for what types of patients, for which diagnoses), which informed the selection of appropriate antimicrobial stewardship interventions chosen by each of the intervention facilities (additional details reported by Chung et al). ${ }^{13}$

Administered antibiotics. All administered anti-infective prescriptions were obtained from hospital computer physician order entry and pharmacy information electronic systems and reported monthly (for patients 18 years or older). Data submissions were for administered drugs and included generic antibiotic names, start and end dates, route of administration, dose given, and dose frequency or dose per day. We requested antibiotic data from all participating hospitals, but only intervention hospitals were able to submit these data.

C. difficile data collection. CDI case definitions were based on prior published criteria. ${ }^{14,15}$ A CDI incident case was defined as a patient 18 years or older with diarrhea without another etiology and with laboratory-confirmed $C$. difficile. The definitions also included categorizations of CDI cases based on possible transmission location. A hospital-onset CDI was defined as a patient with onset of diarrhea and lab confirmation more than 48 hours after admission or symptoms that developed within 48 hours after discharge from the facility. Community-onset CDI was defined as a patient transferred from another healthcare facility with CDI or symptoms and lab confirmation within 48 hours of admission. Community-onset, healthcare facility-associated (CO-HCFA) CDI was defined as a patient discharged from the facility without CDI who was readmitted within 4 weeks and had lab-confirmed CDI. Recurrent cases were defined as cases that occurred within 2-8 weeks after a previous CDI to the same facility/hospital system. ${ }^{11,14-16}$

The Centers for Disease Control and Prevention's NHSN Laboratory-Identified Multidrug-Resistant Organism or CDI Event (LabID) form was used to capture CDI data. ${ }^{16}$ This allowed facilities to comply with concurrent mandatory reporting of CDI to the New York State Department of Health. Additional custom fields were added to the NHSN data capture tool to help compare prior CDI rates obtained during the GNYHA/UHF C. difficile collaborative. ${ }^{14-16}$ The laboratory methods for CDI diagnosis remained stable at each institution during the ERASE study period.

Human subjects. All hospitals received institutional review board (IRB) approval from their internal/contracted 
IRBs. Boston University obtained IRB approval from the Boston University IRB, and GNYHA's participation was approved by the Biomedical Research Alliance of New York IRB.

Analysis. Data from all sources were requested from June 2010-January 2012 (20 months). In an attempt to address potential seasonality in volume of infectious diagnoses, CDI rates, and antibiotic use, we created a matched month data set. Thus, our final analysis used data from June 2010-January 2011 and June 2011-January 2012 (16 months), excluding February 2011-May 2011 (4 months).

Infection control compliance and environmental cleaning compliance were calculated for each facility as well as for intervention and nonintervention groups. Rates of compliance were compared for the 2 times frames.

Antibiotic consumption was measured with 3 distinct measures: defined daily dose (as defined by the World Health Organization [WHO]), ${ }^{17}$ days of therapy, ${ }^{18}$ and number of courses (continuous administration of an antibiotic with less than 48 hours interruption of any 2 doses) prescribed. We examined total antibiotic usage, total target antibiotic usage, total nontarget antibiotic usage, and usage for each individual target antibiotic/class and by each facility. ${ }^{1718}$

Our CDI analysis focused on hospital-onset CDI and COHCFA CDI. Monthly CDI rates per 10,000 patient-days were calculated for each facility as well as for intervention and nonintervention groups.

All patient-level regression models examined the intervention hospitals' antibiotic usage and included hospital fixed effects and robust standard errors (clustered sandwich estimator). These models included time (months), patient age (years), and number of antibiotics taken concurrently as covariates. Defined daily dose and days of therapy models used fixed effects models, while antibiotic courses were evaluated using Poisson models. Logged patient-days were used in the Poisson models to control for the exposure, and a series of interaction terms was used to gauge whether intervention hospitals were able to decrease their hospital-onset CDI cases over time compared with nonintervention hospitals. Additional Poisson models were run using only intervention group hospitals to evaluate whether they were able to reduce their hospital-onset CDI rates per 10,000 patient-days compared with their own baseline rates.

Empirical cut points and patient-level investigation were used to identify outlier cases that may have been the result of error in the reported data (eg, 120 doses administered instead of 20 doses). All analyses were performed using Stata 11.2 statistical software, and we employed an $\alpha$ of 0.05 for all statistical tests, unless otherwise specified. ${ }^{19}$

\section{RESULTS}

The 10 participating hospital facilities were located in $3 \mathrm{New}$ York City boroughs (Manhattan, Bronx, and Brooklyn) and on suburban Long Island. The mean bed size for intervention hospitals was 573 (range, 396-871) compared with 297 beds (range, 212-369) at control hospitals. ${ }^{20,21}$ All were nonprofit facilities and combined had more than 240,000 inpatient admissions annually. Average compliance not only was maintained but also slightly improved during ERASE $C$. difficile compared with the prior $C$. difficile initiative for infection

TA BLE 1. Tailored Antimicrobial Stewardship Interventions Based on Selected Antibiotic Targets

\begin{tabular}{|c|c|c|c|c|c|c|c|}
\hline \multirow[b]{2}{*}{ Targets } & \multirow[b]{2}{*}{ Facility } & \multicolumn{2}{|c|}{ Case control } & \multirow[b]{2}{*}{ Interventions ${ }^{b}$} & \multirow[b]{2}{*}{ Location } & \multirow{2}{*}{$\begin{array}{l}\text { Time intervention } \\
\text { in place }\end{array}$} & \multirow[b]{2}{*}{ Additional details $^{c}$} \\
\hline & & $\mathrm{OR}^{\mathrm{a}}$ & $P$ & & & & \\
\hline Piperacillin/tazobactam & $1-6$ & $4.1-6.1$ & $<.05$ & $\begin{array}{l}\text { Audit and feedback } \\
\text { ( } 6 \text { facilities, } 3 \text { as } \\
\text { newer interven- } \\
\text { tion), restriction } \\
\text { ( } 3 \text { facilities, } 1 \text { as } \\
\text { new ASP } \\
\text { intervention) }\end{array}$ & $\begin{array}{l}\text { Hospital-wide (facili- } \\
\text { ties } 2-5 \text { ), medicine } \\
\text { services (facilities } \\
1,6 \text { ) }\end{array}$ & 6 months to 1 year & $\begin{array}{l}\text { Required additional resources: } \\
\text { clinical pharmacists, phar- } \\
\text { macy residents, or infec- } \\
\text { tious diseases fellows; infor- } \\
\text { mation technology to } \\
\text { identify targets }{ }^{22}\end{array}$ \\
\hline $\begin{array}{l}\text { Quinolone (ciprofloxacin/ } \\
\text { moxifloxacin) }\end{array}$ & $1,2,6$ & $2.0-4.7$ & $<.05$ & $\begin{array}{l}\text { Antibiotic restriction } \\
\text { changes ( } 2 \text { facili- } \\
\text { ties), algorithms ( } 3 \\
\text { facilities) }\end{array}$ & $\begin{array}{l}\text { Hospital-wide (facili- } \\
\text { ties } 1,2,6 \text { ), emer- } \\
\text { gency department } \\
\text { (facility 2) }\end{array}$ & $2-6$ months & $\begin{array}{l}\text { At least } 1 \text { facility automated } \\
\text { screens for algorithms to } \\
\text { prompt prescriber to reeval- } \\
\text { uate choices }\end{array}$ \\
\hline Cefepime & 4,5 & $9.5-9.8$ & $<.05$ & $\begin{array}{l}\text { Audit and feedback } \\
\text { (de-escalation; } 2 \\
\text { facilities) }\end{array}$ & $\begin{array}{l}\text { Hospital-wide, MICU } \\
\text { focus expanded for } \\
\text { facility } 5\end{array}$ & More than 1 year & $\begin{array}{l}\text { Required infectious diseases } \\
\text { clinician's input (outside of } \\
\text { formal consultation); activi- } \\
\text { ties affected limited per- } \\
\text { centage of prescriptions for } \\
\text { that drug }\end{array}$ \\
\hline
\end{tabular}

Note. ASP, antimicrobial stewardship program; MICU, medical intensive care unit; OR, odds ratio.

a OR results from internal facility case control study for potential antibiotic targets.

b Number of facilities that implemented described ASP intervention.

c Each required additional supportive activities, including education, as a result of complexities; time needed to plan, initiate, and have fully operational varied. ${ }^{22,23}$

${ }^{d}$ Includes other broad-spectrum antibiotics. Facilities 4 and 5 had ongoing piperacillin/tazobactam restrictions prior to June 2010. 
TABLE 2. Antibiotic Consumption per 10,000 Patient-Days for Intervention Hospitals

\begin{tabular}{|c|c|c|c|c|c|c|c|c|c|}
\hline \multirow[b]{2}{*}{ Variable } & \multicolumn{3}{|c|}{ Defined daily dose } & \multicolumn{3}{|c|}{ Days of therapy } & \multicolumn{3}{|c|}{ No. of courses } \\
\hline & Mean & SD & Minimum-maximum & Mean & SD & Minimum-maximum & Mean & SD & Minimum-maximum \\
\hline Total & 6,221 & 1,145 & $3,000-8,012$ & 6,258 & 1,706 & $3,333-9,096$ & 1,451 & 382 & $514-1,323$ \\
\hline Nontarget total & 4,303 & 864 & $2,293-5,854$ & 4,124 & 896 & $2,440-5,711$ & 966 & 209 & $514-1,324$ \\
\hline Target total & 1,413 & 535 & $520-2,475$ & 1,601 & 721 & $606-2,778$ & 341 & 161 & $125-596$ \\
\hline Piperacillin/tazobactam & 365 & 326 & $0.155-894$ & 513 & 441 & $0.956-1,153$ & 95 & 80 & $0.96-224$ \\
\hline \multicolumn{10}{|l|}{ Moxifloxacin } \\
\hline Oral & 244 & 1,656 & $14-575$ & 308 & 209 & $17-775$ & 71 & 45 & $9-156$ \\
\hline IV & 45 & 26 & $2-116$ & 46 & 31 & $1.74-140$ & 16 & 12 & $2-46$ \\
\hline \multicolumn{10}{|l|}{ Ciprofloxacin } \\
\hline Oral & 318 & 86 & $143-480$ & 384 & 214 & $129-841$ & 95 & 40 & $39-182$ \\
\hline IV & 280 & 330 & $1-1,029$ & 233 & 277 & $0.956-818$ & 68 & 85 & $0.512-227$ \\
\hline Cefepime & 426 & 222 & $61-847$ & 400 & 246 & $47-877$ & 70 & 44 & $8-150$ \\
\hline
\end{tabular}

NOTE. A total of 108,268 unique episodes of antibiotics were collected (June 2010-January 2011 and June 2011-January 2012). There were 64 nontarget antibiotics, which did not have specific antimicrobial stewardship interventions tailored for their control. IV, intravenous; $\mathrm{SD}$, standard deviation.

control $(86 \%-81 \% ; P=.058)$ and environmental cleaning (98\%-95\%; $P=.028)$.

Table 1 summarizes the case control study results and interventions that were selected at each of the 6 intervention hospitals. Similar antibiotics/classes were found to be significantly associated $(P<.05)$ with CDI in 4 of the 6 hospitals (piperacillin/tazobactam, fluoroquinolones, and cefepime; odds ratios, 2.0-9.8). All hospitals selected at least 1 backend audit and feedback strategy (eg, allowing initiation of empiric antibiotic but assisting prescribers in re-evaluating the antibiotic choice to potentially stop, narrow the spectrum of, or shorten the antibiotic course on the basis of preset criteria, such as cultures, clinical status, or duration of antibiotics) as 1 of their intervention strategies, with up to 3 other interventions implemented per hospital (eg, preauthorization/restriction changes, algorithms, computer changes). Most were implemented hospital-wide and included several supplementary stewardship activities (eg, clinician education).

The 6 intervention hospitals reported a total of 108,268 distinct episodes of antibiotic usage for 68 antibiotics (Table 2 ). Even though prescribing varied, the 4 antibiotic targets accounted for approximately one-third the total usage of all 68 antibiotics.

Tables 3 and 4 summarize descriptive information and regression models assessing overall antibiotic use, total target antibiotic use, nontarget antibiotic use, and specific target antibiotic use over time among all intervention facilities. Our outlier exclusion criteria removed no more than $0.65 \%$ of observations in any of the dependent variables (eg, defined daily dose, days of therapy, and number of courses). Evaluating antibiotic use with defined daily dose, days of therapy, and number of courses did not always yield the same conclusions. For example, the effect of total target antibiotic use on defined daily dose was significantly reduced (fixed effect coefficient, $-0.016 ; P<.05)$ when evaluation was performed with defined daily dose and number of courses (incidence rate ratio [IRR], $0.0995 ; P<.05)$ but not with days of therapy $(-0.012 ; P=.079)$. Using defined daily dose $(P=.099)$ and days of therapy ( $P=.094$ ), oral administration of moxifloxicin was not significantly reduced, but number of courses did show significant reduction (IRR, 0.989; $P<.001$ ) over time. At other times, agreement among the 3 measures was seen (eg, reduction of orally administered ciprofloxacin).

A similar pattern was seen at individual facilities as well. For instance, facility 3 showed a significant reduction for oral ciprofloxacin with the defined daily dose measure $(-0.004$; $P=.016)$ but not as measured by days of therapy $(0.000 ; P$ $=.847)$ or number of courses (IRR, 0.992; $P=.322$ ). At facility 4 , we observed a significant reduction in oral ciprofloxacin using days of therapy $(-0.005 ; P=.014)$ and defined daily dose measures $(-0.009 ; P<.001)$ but not with number of courses (IRR, $0.994 ; P=.226$ ).

Antibiotic doses given at intervention hospitals were compared with the WHO's average adult maintenance dose (which is used to standardize defined daily dose calculations), ${ }^{17}$ and significant discordance was observed. In fact, comparing target antibiotics identified wide variability in the actual doses given at hospitals relative to the WHO defined daily dose average adult maintenance dose in terms of both absolute difference ( -11.13 to $0.5 \mathrm{~g}$ difference) and percent difference ( $-79 \%$ to $100 \%$; data not shown). ${ }^{15}$

Situations where there was good agreement between the facility dosing and the WHO adult maintenance dose seemed to result in parallel changes in defined daily dose and either days of therapy or number of courses (eg, moxifloxacin). Piperacillin-tazobactam was an example in which the prescribed dosing in all facilities was much lower than the WHO defined daily dose adult maintenance dose but did not vary much within or between hospitals over time (data not shown). In this situation, we found it harder to see parallel change among the measures. Interpretation of the measures 
TABLE 3. Description of Target Antibiotics Consumption by 6 Intervention Facilities Antibiotic Usage Measure

\begin{tabular}{|c|c|c|c|c|c|}
\hline Variable & Observations & Mean & SD & Minimum & Maximum \\
\hline Time, months & 108,268 & 10.41 & 6.40 & 1.00 & 20.00 \\
\hline Age & 108,268 & 56.52 & 20.15 & 18.00 & 108.00 \\
\hline No. of antibiotics & 108,268 & 1.80 & 1.16 & 1.00 & 13.00 \\
\hline \multicolumn{6}{|l|}{ Defined daily dose } \\
\hline Total & 105,525 & 7.66 & 12.74 & 0.00 & 323.28 \\
\hline Target total & 105,576 & 1.80 & 4.16 & 0.00 & 146.50 \\
\hline Nontarget total & 85,428 & 7.35 & 35.93 & 0.00 & $6,062.50$ \\
\hline Piperacillin/tazobactam & 105,579 & 0.47 & 1.81 & 0.00 & 43.07 \\
\hline \multicolumn{6}{|l|}{ Moxifloxacin } \\
\hline Oral & 105,579 & 0.16 & 0.92 & 0.00 & 31.00 \\
\hline IV & 105,579 & 0.03 & 0.39 & 0.00 & 23.00 \\
\hline \multicolumn{6}{|l|}{ Ciprofloxacin } \\
\hline Oral & 105,579 & 0.40 & 1.64 & 0.00 & 64.00 \\
\hline IV & 105,579 & 0.22 & 1.85 & 0.00 & 400.00 \\
\hline Cefepime & 105,579 & 0.53 & 3.18 & 0.00 & 500.50 \\
\hline \multicolumn{6}{|l|}{ Days of therapy } \\
\hline Total & 106,122 & 7.72 & 10.01 & 1.00 & 424.00 \\
\hline Target total & 106,176 & 2.01 & 4.06 & 0.00 & 368.00 \\
\hline Nontarget total & 86,457 & 6.20 & 8.16 & 0.00 & 372.00 \\
\hline Piperacillin/tazobactam & 106,176 & 0.65 & 2.24 & 0.00 & 35.00 \\
\hline \multicolumn{6}{|l|}{ Moxifloxacin } \\
\hline Oral & 106,176 & 0.20 & 1.11 & 0.00 & 36.00 \\
\hline IV & 106,176 & 0.03 & 0.37 & 0.00 & 20.00 \\
\hline \multicolumn{6}{|l|}{ Ciprofloxacin } \\
\hline Oral & 106,176 & 0.48 & 1.73 & 0.00 & 36.00 \\
\hline IV & 106,176 & 0.18 & 1.54 & 0.00 & 368.00 \\
\hline Cefepime & 106,176 & 0.47 & 1.99 & 0.00 & 35.00 \\
\hline \multicolumn{6}{|l|}{ No. of courses } \\
\hline Total & 102,170 & 1.86 & 1.30 & 1.00 & 15.00 \\
\hline Target total & 102,170 & 0.45 & 0.67 & 0.00 & 7.00 \\
\hline Nontarget total & 83,207 & 1.50 & 0.92 & 0.00 & 13.00 \\
\hline Piperacillin/tazobactam & 102,170 & 0.12 & 0.35 & 0.00 & 3.00 \\
\hline \multicolumn{6}{|l|}{ Moxifloxacin } \\
\hline Oral & 102,170 & 0.05 & 0.22 & 0.00 & 3.00 \\
\hline IV & 102,170 & 0.01 & 0.10 & 0.00 & 2.00 \\
\hline \multicolumn{6}{|l|}{ Ciprofloxacin } \\
\hline Oral & 102,170 & 0.12 & 0.34 & 0.00 & 3.00 \\
\hline IV & 102,170 & 0.05 & 0.23 & 0.00 & 3.00 \\
\hline Cefepime & 102,170 & 0.09 & 0.29 & 0.00 & 3.00 \\
\hline
\end{tabular}

NOTE. IV, intravenous; SD, standard deviation.

was even more complex for cefepime because of the wide variation from the WHO assigned defined daily dose adult maintenance dose and the actual dosing between hospitals.

Potential changes observed in different antibiotic consumption metrics are influenced by the type of stewardship activities as well as the prescribed daily doses relative to WHO defined daily doses (Figure 1). While the change observed in these metrics may be apparent on their own, the magnitude of their change may be different relative to each other. This could be easily demonstrated using a planned empiric regimen of cefepime for 10 days with audit feedback as the main stewardship intervention activity. If the cefepime dose prescribed is more ( $2 \mathrm{~g}$ every 12 hours) than 1 defined daily dose ( $2 \mathrm{~g}$ per day), then upfront restriction can potentially reduce 20 defined daily doses but decrease days of therapy by only 10 days and course of therapy by only 1 . In contrast, if the actual dose used is lower ( $0.5 \mathrm{~g}$ every 12 hours) than 1 defined daily dose, then this type of intervention can potentially reduce 5 defined daily doses, but the reduction in days of therapy and course of therapy remains unchanged at 10 days and 1 course, respectively. Similar patterns of relative change can be observed with other types of stewardship interventions.

The majority of the 3,491 CDI cases reported in this study were community-onset CDI $(37 \% ; N=1,294)$ cases, followed closely by hospital-onset CDI cases $(35 \% ; N=1,212)$. 
TAB LE 4. Antibiotic Target Measures for the Intervention Group

\begin{tabular}{|c|c|c|c|c|c|c|c|c|c|}
\hline & \multirow[b]{2}{*}{ Total } & \multirow{2}{*}{$\begin{array}{c}\text { Target } \\
\text { total }\end{array}$} & \multirow{2}{*}{$\begin{array}{c}\text { Nontarget } \\
\text { total }\end{array}$} & \multirow{2}{*}{$\begin{array}{l}\text { Piperacillin/ } \\
\text { tazobactam }\end{array}$} & \multicolumn{2}{|c|}{ Moxifloxacin } & \multicolumn{2}{|c|}{ Ciprofloxacin } & \multirow[b]{2}{*}{ Cefepime } \\
\hline & & & & & Oral & IV & Oral & IV & \\
\hline \multicolumn{10}{|l|}{ Defined daily dose } \\
\hline Time, months & -0.048 & $-0.016^{\star *}$ & -0.050 & -0.003 & $-0.002^{*}$ & $-0.001^{* *}$ & $-0.005^{\star *}$ & -0.005 & -0.000 \\
\hline$P$ & .213 & .015 & .276 & .328 & .099 & .042 & .016 & .335 & .902 \\
\hline Age & -0.008 & $0.015^{* *}$ & $-0.029^{*}$ & $0.005^{\star}$ & 0.003 & 0.000 & $0.004^{* *}$ & 0.004 & $-0.00 \mathrm{I}$ \\
\hline$P$ & .452 & .048 & .089 & .056 & .127 & .263 & .028 & .337 & .640 \\
\hline No. of antibiotics & $6.198^{\star * *}$ & $1.530^{\star * *}$ & $4.922^{\star * *}$ & $0.480^{\star *}$ & $0.019^{\star *}$ & $0.025^{\star *}$ & $0.143^{\star * *}$ & 0.200 & $0.661^{* * *}$ \\
\hline$P$ & $<.001$ & $<.001$ & .001 & .011 & .049 & .044 & .010 & .147 & .007 \\
\hline Constant & $-2.704^{\star \star}$ & $-1.678^{\star * *}$ & -0.336 & -0.674 & 0.010 & -0.026 & -0.046 & -0.326 & -0.618 \\
\hline$P$ & .013 & .004 & .824 & .112 & .901 & .218 & .592 & .429 & .128 \\
\hline Observations & 105,525 & 105,576 & 85,428 & 105,578 & 105,579 & 105,579 & 105,576 & 105,578 & 105,577 \\
\hline$R^{2}$ & 0.319 & 0.196 & 0.027 & 0.106 & 0.004 & 0.007 & 0.014 & 0.036 & 0.083 \\
\hline \multicolumn{10}{|l|}{ Days of therapy ${ }^{b}$} \\
\hline Time, months & -0.004 & $-0.012^{\star}$ & 0.001 & -0.007 & $-0.003^{\star}$ & $-0.001^{\star *}$ & $-0.004^{\star \star}$ & -0.003 & 0.006 \\
\hline$P$ & .508 & .079 & .929 & .174 & .094 & .037 & .010 & .434 & .132 \\
\hline Age & $0.025^{\star *}$ & $0.024^{* * *}$ & 0.001 & $0.009^{\star *}$ & 0.003 & 0.000 & $0.005^{\star \star}$ & 0.004 & 0.003 \\
\hline$P$ & .024 & .005 & .864 & .033 & .123 & .303 & .016 & .328 & .217 \\
\hline No. of antibiotics & $6.185^{\star \star *}$ & $1.623^{* * *}$ & $4.078^{* * *}$ & $0.668^{* * *}$ & $0.029^{*}$ & $0.024^{* *}$ & $0.162^{\star *}$ & 0.176 & $0.564^{* *}$ \\
\hline$P$ & $<.001$ & $<.001$ & $<.001$ & .006 & .055 & .034 & .017 & .140 & .023 \\
\hline Constant & $-4.907^{* * *}$ & $-2.193^{* * *}$ & $-1.928^{* * *}$ & $-0.984^{\star}$ & 0.002 & -0.025 & -0.078 & -0.308 & -0.799 \\
\hline$P$ & $<.001$ & .001 & .002 & .081 & .988 & .284 & .549 & .392 & .150 \\
\hline Observations & 106,122 & 106,176 & 86,457 & 106,176 & 106,176 & 106,176 & 106,176 & 106,176 & 106,176 \\
\hline$R^{2}$ & 0.530 & 0.245 & 0.372 & 0.136 & 0.005 & 0.007 & 0.018 & 0.022 & 0.116 \\
\hline \multicolumn{10}{|l|}{ No. of courses ${ }^{b}$} \\
\hline Time, months & 1.000 & $0.995^{\star \star *}$ & $0.999^{* * *}$ & 0.993 & $0.989^{* * *}$ & $0.979^{\star \star \star}$ & $0.989^{* * *}$ & $0.988^{* * *}$ & $1.016^{\star * *}$ \\
\hline$P$ & .670 & .001 & .004 & .341 & $<.001$ & .001 & .004 & $<.001$ & .003 \\
\hline Age & $1.001^{\star * *}$ & $1.014^{\star * *}$ & $0.998^{\star * *}$ & $1.016^{* * *}$ & $1.015^{* * *}$ & $1.018^{* * *}$ & $1.011^{* * *}$ & $1.018^{* * *}$ & $1.013^{* * *}$ \\
\hline$P$ & $<.001$ & $<.001$ & $<.001$ & $<.001$ & $<.001$ & $<.001$ & $<.001$ & $<.001$ & $<.001$ \\
\hline No. of antibiotics & $1.439^{* * *}$ & $1.496^{* * *}$ & $1.338^{* * *}$ & $1.654^{* * *}$ & $1.121^{\star * *}$ & $1.434^{* * *}$ & $1.201^{\star \star \star}$ & $1.517^{\star * *}$ & $1.882^{* * *}$ \\
\hline$P$ & $<.001$ & $<.001$ & $<.001$ & $<.001$ & $<.001$ & $<.001$ & $<.001$ & $<.001$ & $<.001$ \\
\hline Observations $^{\mathrm{b}}$ & 102,170 & 102,170 & 83,207 & 102,170 & 63,224 & 63,224 & 102,170 & 102,170 & 102,170 \\
\hline
\end{tabular}

NOTE. IV, intravenous.

a Modeled with fixed effects regression.

b Modeled with Poisson regression with results presented as incidence rate ratios.

' Insufficient data of moxifloxacin (IV and oral routes) in 3 hospitals caused reduced number of usable observations in course models.

* Significant at .10

** Significant at .05 .

*** Significant at .01 


\begin{tabular}{|c|c|c|c|}
\hline Modifying Scenarios & $D D D$ & DOT & Course \\
\hline $\begin{array}{l}\text { Prevent initiation of antibiotics due to } \\
\text { restriction } \\
\text { - If patient's daily dose to DDD ratio }>1 \\
\text { - If patient's daily dose to DDD ratio } \sim 1 \\
\text { - If patient's daily dose to DDD ratio }<1\end{array}$ & $\begin{array}{c}\downarrow \downarrow \downarrow \\
\downarrow \downarrow \\
\downarrow \downarrow\end{array}$ & $\begin{array}{l}\downarrow \downarrow \\
\downarrow \downarrow \\
\downarrow \downarrow \downarrow\end{array}$ & $\begin{array}{l}\downarrow \\
\downarrow \\
\downarrow\end{array}$ \\
\hline $\begin{array}{l}\text { Audit feedback at } 72 \text { hours to stop antibiotics } \\
\text { - If patient's daily dose to DDD ratio }>1 \\
\text { - If patient's daily dose to DDD ratio } \sim 1 \\
\text { - If patient's daily dose to DDD ratio }<1\end{array}$ & $\begin{array}{l}\downarrow \downarrow \\
\downarrow \\
\downarrow\end{array}$ & $\begin{array}{c}\downarrow \\
\downarrow \\
\downarrow \downarrow\end{array}$ & $\begin{array}{l}\leftrightarrow \\
\leftrightarrow \\
\leftrightarrow\end{array}$ \\
\hline $\begin{array}{r}\text { Decrease daily dose based on algorithms } \\
\text { - If patient's daily dose to DDD ratio }>1 \\
\text { - If patient's daily dose to DDD ratio } \sim 1 \\
\text { - If patient's daily dose to DDD ratio }<1 \\
\end{array}$ & $\begin{array}{l}\downarrow \\
\downarrow \\
\downarrow\end{array}$ & $\begin{array}{l}\leftrightarrow \\
\leftrightarrow \\
\leftrightarrow\end{array}$ & $\begin{array}{l}\leftrightarrow \\
\leftrightarrow \\
\leftrightarrow\end{array}$ \\
\hline $\begin{array}{l}\text { Decrease length of therapy } \\
\text { - If patient's daily dose to DDD ratio }>1 \\
\text { - If patient's daily dose to DDD ratio } \sim 1 \\
\text { - If patient's daily dose to DDD ratio }<1\end{array}$ & $\begin{array}{c}\downarrow \downarrow \\
\downarrow \\
\downarrow\end{array}$ & $\begin{array}{c}\downarrow \\
\downarrow \\
\downarrow \downarrow\end{array}$ & $\begin{array}{l}\leftrightarrow \\
\leftrightarrow \\
\leftrightarrow\end{array}$ \\
\hline
\end{tabular}

FIGURE 1. Antibiotic measure comparisons. Arrows represent the relative decrease or lack of effect that specific antibiotic stewardship activities may have on the 3 antibiotic measures listed. Course, distinct antibiotic courses started or stopped within a given period; DDD, defined daily dose; DOT, days of therapy.

CO-HCFA CDI cases accounted for $19 \%(N=676)$, and $9 \%(N=309)$ were classified as recurrent cases. The rate of hospital-onset CDI per 10,000 patient-days was observed to differ between the intervention and control hospitals. On average, intervention hospitals reported slightly fewer hospital-onset CDI cases ( -2.8 rate point difference) as well as slightly fewer hospital-onset CDI combined with CO-HCFA CDI cases per 10,000 patient-days $(-3.9$ rate point difference), which were not statistically significantly different. In Figure 2, the intervention group hospital-onset CDI rates (dashed line) appear to be lower at the end of the project compared with the beginning, but this trend was not statistically significant. Hospital-onset CDI rates for control hospitals (solid line) remained fairly static over time.

Poisson models were used to evaluate the hospital-onset CDI reduction over time in intervention hospitals compared with controls, and another series of Poisson models was used to investigate whether intervention hospitals reduced their hospital-onset CDI burden compared with their baseline rates. Both of these approaches suggested a trend toward reducing hospital-onset CDI rates over time (results not shown), which was not statistically significant. Analysis was also done including hospital-onset CDI and CO-HCFA CDI, which were not statistically significant (data not shown).

\section{DISCUSSION}

The ERASE C. difficile project was designed to implement and evaluate antimicrobial stewardship interventions as a method for reducing hospital-onset CDI. Intervention hos- pitals reduced the use of targeted antibiotics to varying degrees, depending on the measures used for evaluation and interventions implemented. While these reductions could not be definitively associated with reductions in hospital-onset CDI rates, the knowledge gained from implementing ASP activities tailored to CDI offered valuable lessons.

Intervention hospitals reduced at least 1 of their antibiotic targets as measured by defined daily dose, days of therapy, or number of courses. However, the different antibiotic measures produced inconsistent interpretation of antibiotic usage patterns over time. When large changes in prescribing were seen, such as with the fluoroquinolone agents, we observed change in more than 1 measure, usually in parallel. However, for some antibiotics, these parallel changes were less likely to be observed. Our findings suggest that discordance between WHO average adult doses and prescribed doses may be responsible, and this finding is consistent with prior work. ${ }^{17,18}$

Assessing antibiotic use was even more complex than simply studying the measures. Our data suggest that interventions also influence the measure's behavior. Although antimicrobial stewardship interventions may influence all of the antibiotic measures, in some circumstances, 1 measure may be more likely to show an impact compared with others. For example, an intervention that restricts an antibiotic from being started will likely affect the number of courses measure and, subsequently, the days of therapy and defined daily doses-but to different degrees-because preventing a patient from receiving an antibiotic would not necessarily affect the days of therapy for a patient who does receive it. An audit activity 


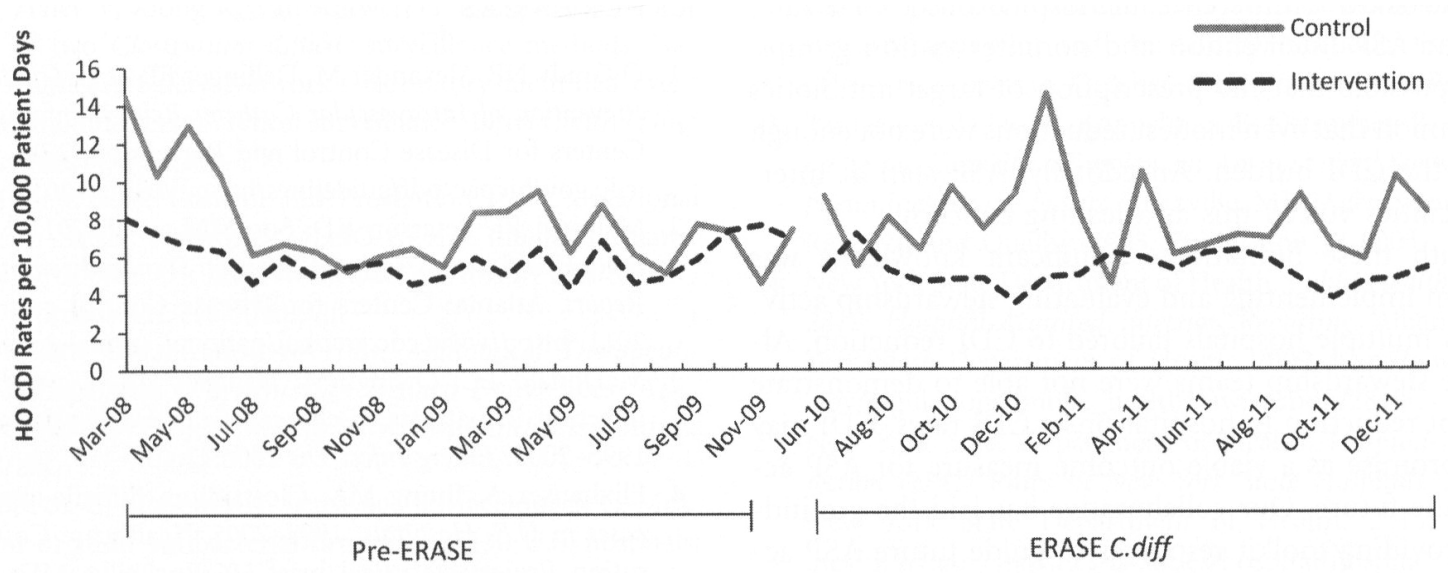

FIGURE 2. Hospital-onset Clostridium difficile infection (HO CDI) rates by facilities group. Graph compares the rates of HO CDI for antimicrobial stewardship program intervention and nonintervention facilities from the prior $C$. difficile collaborative through the Evaluation and Research on Antimicrobial Stewardship's Effect (ERASE) project time frame. The 5 months of missing CDI rates on the graph represent the 5 months after the initial collaborative concluded but before initial data collection began for the ERASE project.

that reviews antibiotics at a set time, such as at 72 hours, will more likely affect days of therapy and defined daily doses but will be unlikely to affect number of courses. Stewardship activities are often mixed and could limit both the start and the length of treatment, which could affect more than 1 antibiotic measure to varying degrees.

Polk et $\mathrm{al}^{18}$ has previously described factors that may influence the use of the defined daily dose measure: (1) variation from the WHO defined daily dose, (2) variation in dose and/or interval between facilities, and (3) changes in dosing over time. Our data suggest that an additional factor to consider is the variation in the ability of different antibiotic measures to detect different prescribing changes. In reviewing the pros and cons of each measure, none are perfect, but days of therapy seemed less influenced by dosing schemas compared with defined daily doses. These observations could inform other attempts to evaluate antibiotic usage for either ASP research or practical applications.

The implementation of ASP interventions was typically more complex than expected, and there is no 1 size fits all model. Each site developed ASP activities that met its unique needs, reflected its current interdepartmental relationships, responded to its existing prescribing practices, and considered local resource constraints. Most interventions needed to be coupled with educational activities, and the facilities needed to be creative about where to identify supplemental staffing for ASP activities, because additional staff were not hired. . $^{12,22,23}$

This study was not able to demonstrate a statistically significant reduction in the incidence of hospital-onset CDI among the intervention hospitals compared with the nonintervention facilities. The length of time interventions were fully in place was much shorter than anticipated because of the need for a longer rollout period. We had originally planned to allow for a 6-month baseline period and expected that hospitals would take 3 months to fully implement their intervention(s) of choice, allowing for a 10 -month postintervention period followed by an interrupted time series analysis. In fact, a lengthy rollout period of approximately 15 months was required for most ASP activities, rendering the full implementation observation period considerably shorter than anticipated ( 3 months). These unforeseen obstacles forced changes in our planned analytic approach and likely resulted in insufficient time to detect a change.

There are several limitations to the internal and external validity of our study. The New York State Department of Health began mandatory collection and public reporting of $\mathrm{CDI}$ rates approximately 1 year before our project began ${ }^{24,25}$ In order to use the data from the prior GNYHA/UHF $C$. difficile collaborative as a baseline, a slightly different definition of the CDI categories (hospital-onset CDI and COHCFA CDI) was used. However, CDI cases using the NHSN definitions were available throughout our study period, and the prior CDI definition variations were validated. ${ }^{15,16}$ Mandatory public reporting may have accounted for the reduction in CDI in both the intervention and nonintervention facilities. Furthermore, although the nonintervention hospitals did not have formal stewardship, they may have still benefited from participating in this network. The nonintervention facilities did not have the computer systems or resources (eg, information technology) to systemically capture or summarize aggregate antibiotic use; thus, no comparison of their use over time was possible. Given that the intervention facilities had young stewardship programs as opposed to no stewardship at baseline, it is possible that we missed CDI reductions realized soon after ASP implementation. The intervention facilities were much larger than the nonintervention facilities and thus may not have been a good comparison group. However, recent data suggest that CDI rates are likely to be higher in smaller facilities with more private or nonteaching prescribers. ${ }^{5,7}$ Thus, if anything, this may have made 
it harder to show a difference in hospital-onset CDI rates between the ASP intervention and nonintervention groups. Last, it is possible that the prescription of target antibiotics was so common that even modest reductions were not enough to impact the CDI burden. Anecdotally, ASP staff at intervention facilities voiced this as a leading concern.

Even with these limitations, significant knowledge was gained from implementing and evaluating stewardship activities across multiple hospitals tailored to CDI reduction. Although the stewardship teams were not able to demonstrate a significant reduction in hospital-onset CDI rates, CDI may still hold promise as a viable outcome measure for ASP activities in the future. Our collaborative has laid the groundwork in providing toolkit resources to guide future ASP activities targeting CDI. ${ }^{12}$ This is particularly important in that ASP was evaluated in this study as a CDI control measure in a setting with a preexisting high level of compliance with infection control and environmental practices designed to control CDI (essential in our best understanding of CDI control). Thus, this should not be an indictment of ASP but a further call to identify the most effective ways to study, measure, and operationalize ASP for improving antibiotic prescribing in general and specifically as part of multipronged approaches including complementary CDI hospital control activities. The results may also inform potential policy decisions regarding the public use of CDI control measures, including ASP initiatives, for measuring hospital quality and safety. ${ }^{26,27}$

\section{ACKNOWLEDGMENTS}

We would like to thank Kathy Crosson, Darryl Gray, and James Cleeman of the Agency for Healthcare Research and Quality (AHRQ) and Carolyn Gould of the Centers for Disease Control and Prevention for coordinating and supporting this project; the Evaluation and Research on Antimicrobial Stewardship's Effect on Clostridium difficile participating facilities for ongoing collaboration; and Liise-Anne Pirofski, Mark Sinett, and Frank Sosnowski for their incredible support to the Montefiore/Einstein antimicrobial stewardship program team.

Financial support. This project was funded under contract HHSA290200600012i T0\#10 from the AHRQ and the US Department of Health and Human Services (HHS) via the AHRQ ACTION initiative to Boston University. The opinions expressed in this document are those of the authors and do not reflect the official position of AHRQ or HHS.

Potential conflicts of interest. P.R. reports receiving grants during the course of this study from Cubist Pharmaceutical, Optimer Pharmaceutical, and $\mathrm{BD}$ GeneOhm outside of this work as well as having a patent pending for rapid diagnosis of $C$. difficile. All other authors report no conflicts of interest relevant to this article. All authors submitted the ICMJE Form for Disclosure of Potential Conflicts of Interest, and the conflicts that the editors consider relevant to this article are disclosed here.

Address correspondence to Belinda Ostrowsky, MD, MPH, FSHEA, Montefiore Medical Center, Albert Einstein College of Medicine, 111 East 210 Street, Bronx, NY 10467 (bostrows@montefiore.org).

\section{REFERENCES}

1. O'Grady NP, Alexander M, Dellinger EP, et al. Guidelines for the Prevention of Intravascular Catheter-Related Infections. Atlanta: Centers for Disease Control and Prevention, 2011. http://www .cdc.gov/hicpac/pdf/guidelines/bsi-guidelines-2011.pdf.

2. Malpiedi PJ, Peterson KD, Soe MM, et al. 2011 National and State Healthcare-Associated Infection Standardized Infection Ratio Report. Atlanta: Centers for Disease Control and Prevention, 2011. http://www.cdc.gov/hai/national-annual-sir/index.html.

3. McDonald LC, Owings M, Jernigan DB. Clostridium difficile infection in patients discharged from US short-stay hospitals, 1996-2003. Emerg Infect Dis 2006;12:409-415.

4. Elixhauser A, Jhung MA. Clostridium difficile-associated Diseases in U.S. Hospitals, 1993-2005. Healthcare Cost and Utilization Project statistical brief 50. Rockville, MD: Agency for Healthcare Research and Quality, 2008. http://www.hcup-us .ahrq.gov/reports/statbriefs/sb50.jsp.

5. Lessa FC, Gould CV, McDonald LC. Current status of Clostridium difficile infection epidemiology. Clin Infect Dis 2012;55(S2): S65-S70.

6. Redelings MD, Sorvillo F, Mascola L. Increase in Clostridium difficile-related mortality rates, United States, 1999-2004. Emerg Infect Dis 2007;13:1417-1419.

7. Chitnis AS, Holzbauer SM, Belflower RM, et al. Epidemiology of community-associated Clostridium difficile infection, 2009 through 2011. JAMA Intern Med 2013;173:1359-1367.

8. Cohen SH, Gerding DN, Johnson S, et al. Clinical practice guidelines for Clostridium difficile infection in adults: 2010 update by the Society for Healthcare Epidemiology of America (SHEA) and the Infectious Diseases Society of America (IDSA). Infect Control Hosp Epidemiol 2010;31:431-455.

9. Dellit T, Owen R, McGowan J, Gerding D, Weinstein J, Burke J. Infectious Diseases Society of America and the Society for Healthcare Epidemiology of America guidelines for developing an institutional program to enhance antimicrobial stewardship. Clin Infect Dis 2007;44:159-177.

10. Moody J, Cosgrove S, Olmstead R, et al. Antimicrobial stewardship: a collaborative partnership between infection preventionists and healthcare epidemiologists. Infect Control Hosp Epidemiol 2012;33(4):328-330.

11. Koll B, Ruiz R, Calfee B, et al. Prevention of hospital-onset Clostridium difficile infection in the New York metropolitan region using a collaborative intervention model. J Healthc Qual 2014;36:35-45.

12. Agency for Healthcare Research and Quality (AHRQ). Toolkit for Reduction of Clostridium difficile Infections Through Antimicrobial Stewardship: The Evaluation and Research on Antimicrobial Stewardship's Effect on Clostridium difficile (ERASE C. difficile) Project. Rockville, MD: AHRQ, 2012. http://www .ahrq.gov/qual/cdifftoolkit/cdiffllqu.htm.

13. Chung P, Guo Y, Ostrowsky B. Does choice of control group affect the association of antibiotics with Clostridium difficileassociated diarrhea? In: SHEA 2011 Annual Scientific Meeting; April 1-4, 2011; Dallas, TX. http://shea.confex.com/shea/2011 /webprogram/Paper4443.html.

14. McDonald L, Coignard B, Dubberke E, Song X, Horan T, Kutty P. Ad hoc Clostridium difficile surveillance working group recommendations for surveillance $C$. difficile-associated disease. Infect Control Hosp Epidemiol 2007;28:140-145. 
15. Gase K, Haley V, Xiong K, Van Antwerpen C, Stricof R. Comparison of two Clostridium difficile surveillance methods: $\mathrm{Na}$ tional Healthcare Safety Network's laboratory-identified event reporting module versus clinical surveillance. Infect Control Hosp Epidemiol 2013;34(3):284-290.

16. Centers for Disease Control and Prevention (CDC), National Healthcare Safety Network. MDRO-CDAD Module. Atlanta: CDC, 2008. http://www.cdc.gov/nhsn/PDFs/MDRO _CDADprotocolv41Dec08final.pdf.

17. World Health Organization (WHO). Anatomical Therapeutic Chemical Classification System with Defined Daily Doses (ATC/ $D D D)$. Geneva: WHO, 2014. http://www.who.int/classifications /atcddd/en/.

18. Polk RE, Fox C, Mahoney A, Letcavage J, MacDougall C. Measurement of adult antibacterial drug use in 130 U.S. hospitals: comparison of defined daily dose and days of therapy. Clin Infect Dis 2007;44(5):664-670.

19. StataCorp. Stata Statistical Software: Release 11.2. College Station, TX: StataCorp, 2009.

20. Centers for Medicare and Medicaid Services (CMS). Healthcare Cost Report Information System. Baltimore, MD: CMS, 2009. http://www.resdac.org/cms-data/files/hcris.

21. New York State Department of Health. Hospital Profiles Report. Albany, NY: New York State Department of Health, 2013. http://www.health.ny.gov/facilities/hospital/.

22. Brown C, Guo Y, Chung P, Brown S, Ostrowsky B. Feasibility and acceptability of an audit and feedback method of antibiotic stewardship: a pilot study. In: Annual Infectious Diseases Society of America meeting; October 2011; Boston, MA. Poster 31615.

23. VanDeusen Lukas C, Koppelman E, Ostrowsky B, et al. Developing the Capacity to Implement Antimicrobial Stewardship: Opportunities for the Future. Rockville, MD: Agency for Healthcare Research and Quality, 2013. Publication 14-0003.

24. New York State Department of Health. Public Health Law Section 2819: Hospital-Acquired Infection Reporting. Albany, NY: New York State Department of Health, 2009. http://www.health.ny .gov/regulations/public_health_law/section/2819/.

25. New York State Department of Health. Hospital-Acquired Infection (HAI) Rates in New York State Hospitals. Albany, NY: New York State Department of Health, 2013, http://www .health.ny.gov/statistics/facilities/hospital/hospital_acquired _infections/.

26. US Department of Health and Human Services and Centers for Medicare and Medicaid Services. Adoption of NHSN C. diffinto FY 2017 Hospital-Acquired Condition Reduction Program. Federal Register, August 19, 2013:50717.

27. US Department of Health and Human Services and Centers for Medicare and Medicaid Services. CMS Intent to Propose Inclusion of NHSN C. diff into FY 2017 Value-Based Purchasing Program in FY 2015 Inpatient Prospective Payment System Proposed Rule. Federal Register, August 19, 2013:50717. 